\title{
EFFECT OF PULSED ELECTRODE WIRE FEEDING ON FORMATION AND WEAR RESISTANCE OF DEPOSITED BEAD AND LOSSES OF ELECTRODE METAL IN CO2 ARC SURFACING
}

\author{
I.V. LENDEL ${ }^{1}$, S.Yu. MAKSIMOV ${ }^{1}$, V.A. LEBEDEV ${ }^{1}$ and O.A. KOZYRKO ${ }^{2}$ \\ ${ }^{1}$ E.O. Paton Electric Welding Institute, NASU \\ 11 Bozhenko Str., 03680, Kiev, Ukraine. E-mail: office@paton.kiev.ua

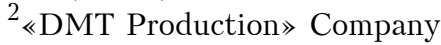 \\ $11 / 2$ Bugsky Bld., 54029, Nikolaev, Ukraine. E-mail: o.kozurko@dmt-wiches.com
}

\begin{abstract}
The work deals with the results of investigations of influence of pulsed electrode wire feed parameters on the conditions of deposited metal bead formation, wear resistance and losses of electrode metal in electric arc surfacing in $\mathrm{CO}_{2}$. The comparative analysis of results was carried out obtained at constant and pulsed electrode wire feed. It was shown that change in electrode wire feed rate at constant power parameters of surfacing process allows efficiently influencing the formation of deposited bead, wear resistance and amount of losses of electrode metal. The given result is achieved due to change of kinematical conditions of electrode metal transfer from the electrode end through the arc gap to the molten metal pool. 11 Ref., 4 Figures.
\end{abstract}

$\boldsymbol{K} \boldsymbol{e} \boldsymbol{y} \boldsymbol{w} \boldsymbol{O} \boldsymbol{r} \boldsymbol{s}:$ deposited metal, electrode wire pulsed feed parameters, geometric parameters of deposited bead, electrode wire feed rate, losses of electrode metal, control of electrode metal transfer

The most important field of the modern welding science and technology is surfacing. The methods of arc surfacing acquired a dominated position in industrial practice. One of the widespread methods remains surfacing in pure $\mathrm{CO}_{2}$. However, this process has a number of disadvantages, the main of which are the following: large penetration depth of base metal; high losses of electrode metal for spattering (from 5 to $15 \%$ ); narrow range of surfacing modes with producing a satisfactory bead formation etc. [1, 2].

The studies, aimed at eliminating disadvantages and improving this technological process, are the subject of numerous works, from which it follows that conditions for formation of deposited metal and manufacturability of arc surfacing in $\mathrm{CO}_{2}$ are determined to a large extent by the possibility of implementation of controllable transfer of molten electrode metal to the weld pool [3, 4].

The effect on electrode metal transfer at constant rate of electrode wire feeding and pulse control of electric parameters of welding arc was realized by such producers like EWM, OTC Daihen, Kemppi, Cloos, ESAB and a number of others. Fronius realized a combined electric mechanical control [5-10].

(c) I.V. LENDEL, S.Yu. MAKSIMOV, V.A. LEBEDEV and O.A. KOZYRKO, 2015
A very scarce information is available in literature on the possibilities of control of molten electrode metal transfer only due to the change in electrode wire feed rate using control circuits of electric parameters of serial sources of welding current.

For these investigations a unique mechanism of pulsed electrode wire feed was designed at the E.O. Paton Electric Welding Institute ( $\mathrm{Fi}^{-}$ gure 1) which allows controlling the electrode metal transfer without using the feedback with welding current source.

The investigations of effect of the pulsed electrode wire feed on geometric sizes of deposited bead were carried out for characteristic ranges of parameters of surfacing in $\mathrm{CO}_{2}$, at which a satisfactory formation of surface of the deposited metal is preserved: surfacing current varied in the range of $80-400 \mathrm{~A}$ and arc voltage was $14-$ $38 \mathrm{~V}$, surfacing speed was $7 \mathrm{~mm} / \mathrm{s}$, electrode stickout was $12 \mathrm{~mm}$, consumption of shielding gas was $0.3 \mathrm{l} / \mathrm{s}$, diameter of nozzle was $20 \mathrm{~mm}$. Power sources Kemppi FastMIG KMS-500 and VDU-506 were applied. The base metal was steel St3. Electrode wires Sv-08G2S and Np-30KhGSA of $1.2 \mathrm{~mm}$ diameter were applied.

The results of carried out investigations show the ability to efficiently influence geometric parameters of bead, to adjust penetration depth of base metal in the frequency range of $10-60 \mathrm{~Hz}$ and pulse duration ratio of $1.25-5$ units (Figure 2). As compared with constant electrode 


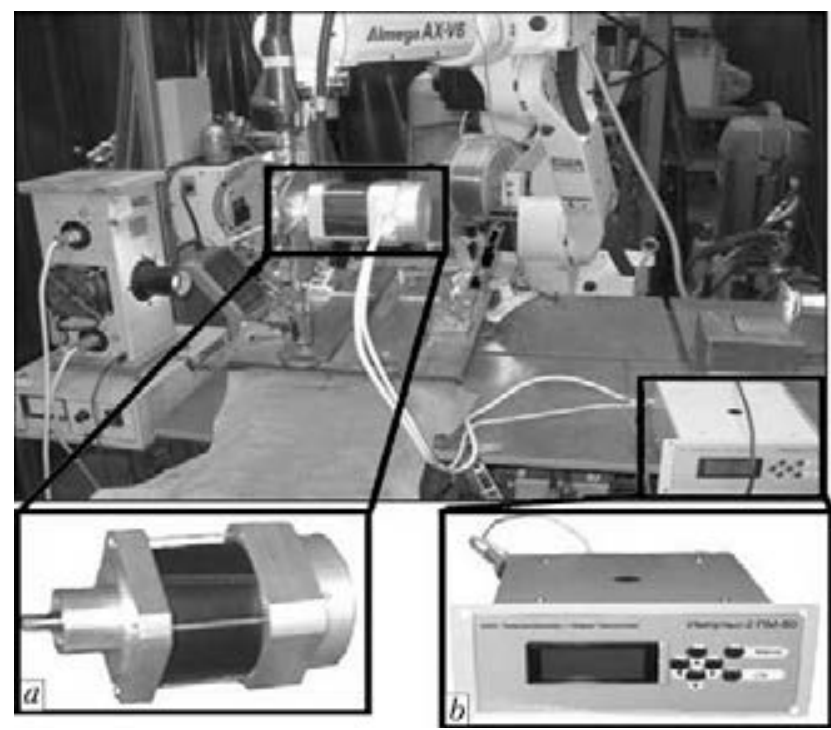

Figure 1. Mechanism of pulsed electrode wire feed installed to the welding robot: $a$ - brushless direct current motor; $b$ - drive control unit

wire rate, it is possible to reduce penetration depth by $1.2-2$ times by using the pulsed feed.

In addition, simultaneously with study of the effect of pulsed wire feed on the geometric parameters of deposited bead, its effect on the loss of electrode metal was studied. The obtained data show that pulsed electrode wire feed allows reducing the loss of electrode metal for spattering by $1.1^{-2}$ times by creating a more favorable conditions for transition of electrode metal drop to the weld pool, which is particularly effective when the frequency of pulses is $20-50 \mathrm{~Hz}$ and pulse duration ratio is 3-5 units (Figure 3 ).

To study the effect of pulsed electrode wire feed on wear resistance of deposited metal the experiments on single- and five-layer surfacing using wire Np-30KhGSA with feeding frequency

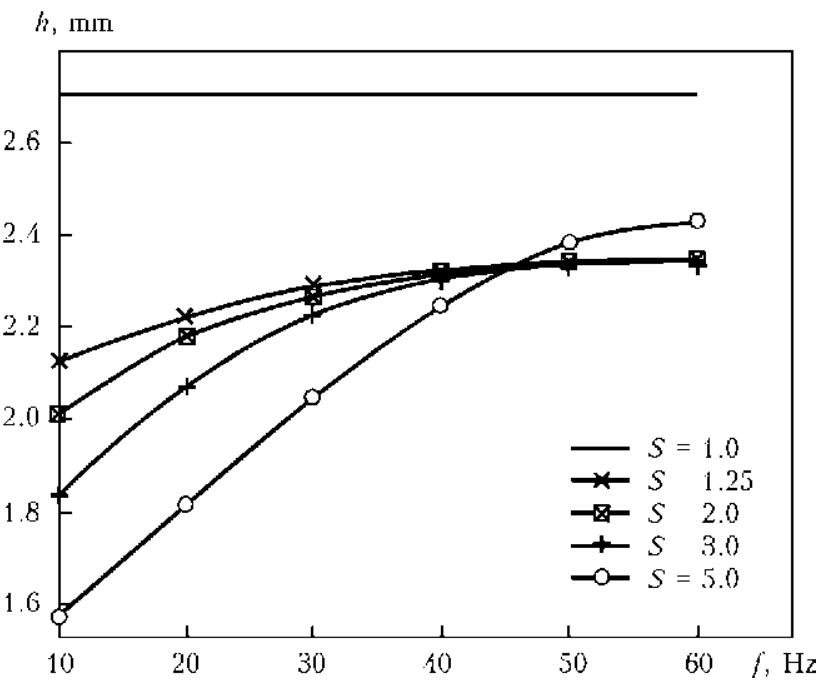

Figure 2. Dependence of penetration depth $h$ on frequency $f$ and pulse duration ratio $S$ of pulsed electrode wire feed at mean current $I=220 \mathrm{~A}$ and voltage $U=26 \mathrm{~V}$ $\psi, \%$

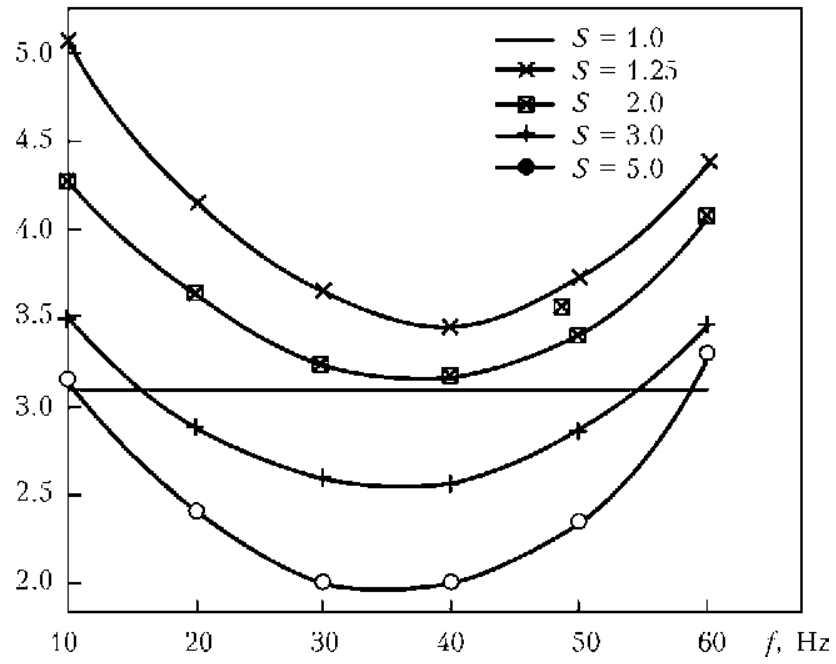

Figure 3. Dependence of losses of electrode metal $\psi$ on frequency $f$ and pulse duration ratio $S$ of pulsed electrode wire feed at mean current $I=220 \mathrm{~A}$ and voltage $U=26 \mathrm{~V}$

of 15,20 and $60 \mathrm{~Hz}$ and pulse duration ratio of 3-5 units were performed.

The tests for wear resistance by friction of metal against metal were carried out at the facility for comprehensive evaluation of deposited metal properties designed at the E.O. Paton Electric Welding Institute [11] under the following conditions: specific pressure at contact point was $100 \mathrm{MPa}$; friction speed was $11-12 \mathrm{~m} / \mathrm{min}$; temperature of ring-counterbody (according to GOST 12423-66) was $23 \pm 2{ }^{\circ} \mathrm{C}$; temperature at the surface of test specimen in contact zone was $30-40{ }^{\circ} \mathrm{C}$; testing time was $1 \mathrm{~h}$. The sizes of ringcounterbody manufactured of hardened steel 45 are as follows: $110 \mathrm{~mm}$ diameter, $30 \mathrm{~mm}$ width, $20 \mathrm{~mm}$ thickness; specimen sizes are $10 \times 20 \times$ $\times 40 \mathrm{~mm}$. For comparison, as a reference the specimens were tested produced at constant electrode wire feed. Wear resistance was evaluated

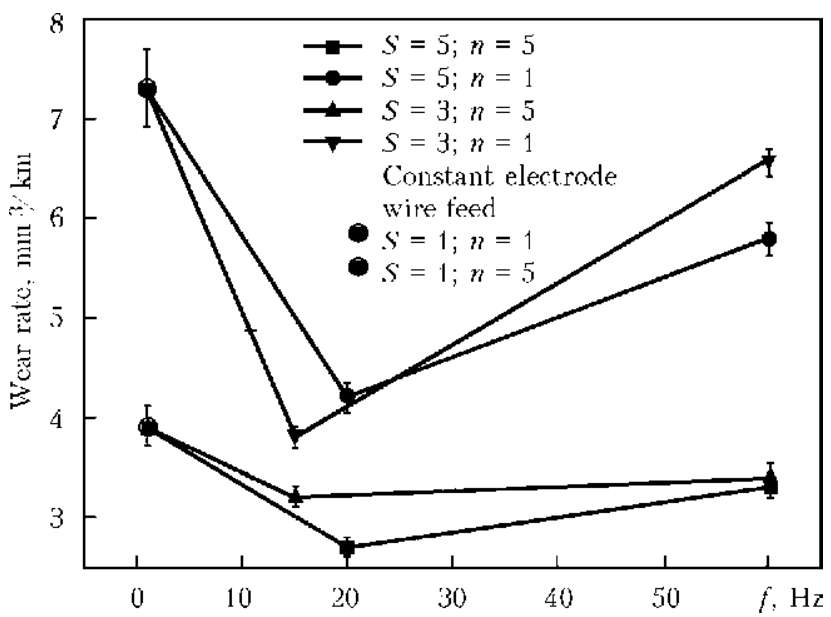

Figure 4. Plot of wear rate of specimens depending on frequency, pulse duration ratio and number $n$ of deposited layers at mean current $I=220 \mathrm{~A}$ and voltage $U=26 \mathrm{~V}$ 
by loss of mass $\Delta G$ of the test specimen and the abrading ring before and after the wear.

The obtained results showed that at pulsed electrode wire feed with low frequency of 15$20 \mathrm{~Hz}$ and pulse duration ratio of 3-5 units, level of wear resistance of fifth deposited layer produced at constant electrode wire feed can be reached already in the first deposited layer, and as compared with a single-layer deposit produced at constant electrode wire feed the wear resistance is almost 2 times higher (Figure 4).

Thus, according to the results of carried out investigations of the effect of pulsed electrode wire feed on formation of deposited bead, wear resistance and losses of electrode metal, the following conclusions were made:

1. The pulsed electrode wire feed allows controlling the geometry of deposited bead. In particular, at current of $220 \mathrm{~A}$ and voltage of $26 \mathrm{~V}$ the penetration depth is 2 times reduced. The increase in frequency from 10 to $60 \mathrm{~Hz}$ results in increase of penetration depth from 1.5 to $2.4 \mathrm{~mm}$, that is closer to the value obtained at constant electrode wire feed.

2. At pulsed electrode wire feed with frequencies of $20-50 \mathrm{~Hz}$ and pulse duration ratio of $3-5$ units the reduction of electrode metal losses is observed. At frequency of $30-40 \mathrm{~Hz}$ and pulse duration ratio of 5 units the minimum losses of electrode metal are provided, that is 2 times lower than those at constant electrode wire feed.
3 . The pulsed electrode wire feed at frequency of pulses of $15-20 \mathrm{~Hz}$ and pulse duration ratio of 3-5 units provides the characteristics of wear resistance even in the first layer similar to those of the fifth deposited layer produced at constant electrode wire feed. Also the improvement of wear resistance by almost 2 times is observed in single-layer surfacing and by 1.5 times - in fivelayer one.

1. Paton, B.E. (1999) Problems of welding at the border of centuries. Avtomatich. Svarka, 1, 4-14.

2. Ryabtsev, I.A., Senchenkov, I.K. (2013) Theory and practice of surfacing works. Kiev: Ekotekhnologiya.

3. Krampit, N.Yu. (2009) Methods of control of electrode metal melting and transfer (Review). Svarochn. Proizvodstvo, 3, 31-35.

4. Zhernosekov, A.M. (2012) Tendencies in development of control of metal transfer processes in shielding gases (Review). The Paton Welding J., 1, 29-33.

5. Goecke, S.F. (2005) Low energy arc joining process for materials sensitive to heat. EWM Hightec Welding $\mathrm{GmbH}$

6. (2013) OTC Daihen Inc. advanced welding and robotic systems. $D P-400 / D P-500 / D M-350 / D M-500$ digital controlled DC inverter arc welding machines: Cat. No. A446C.

7. Uusitalo, J. (2006) Kemppi Pro News 2/2006. FastROOT Process, 4-8.

8. (2008-2009) Kemppi Product Cat. Kemppi Oy. P.O. Box 13. 15801 Lahti, Finland.

9. (2011) Cloos Products, 142. Carl Cloos Schweisstechnik GmbH.

10. (2014/2015) Product Catalogue, 120. Fronius International GmbH, Austria.

11. Ryabtsev, I.I., Chernyak, Ya.P., Osin, V.V. (2004) Block-modular unit for testing of deposited metal. Svarshchik, 1, 18-19. 